\title{
Disagreements in moral intuition as defeaters
}

\begin{abstract}
:
People may disagree about moral issues because they have fundamentally different intuitions. I argue that we ought to suspend judgment in such cases. Since we trust our own moral intuitions without positive evidence of their reliability, we must necessarily extend this trust to the moral intuitions of others: a fundamental self-other asymmetry in moral epistemology is untenable. This ensures that disagreements in moral intuition are defeating. In addition, I argue that brute conflicts in moral intuition require suspension of judgment only if we are required to exhibit this kind of default trust with respect to the moral intuitions of others.
\end{abstract}

\section{Introduction}

Moral disagreement is widespread. Some disagreements are shallow, but others seem deep: they apparently cannot be traced to ignorance of relevant non-moral facts or failures of epistemic rationality, reflecting instead fundamental differences in people's moral intuitions. ${ }^{1}$ Let's call these brute conflicts in intuition. In this paper, I'll try to convince you that we ought to suspend judgment when we knowingly encounter disagreements of this kind.

To do so, I'll argue for the following principle:

\footnotetext{
${ }^{1}$ For recent empirical evidence, see Doris \& Plakias (2008), Abarbanell \& Hauser (2010). Of course, not all conflicts in intuition are fundamental in this sense. There are cases in which divergent intuitions are themselves explained at a deeper level in terms of differences in knowledge of relevant non-moral facts: e.g., conflicting intuitive responses to policies permitting torture may be explained by differences in knowledge regarding the psychological effects of torture. Thanks to an anonymous referee for raising this issue.
} 


\section{The Concessive Principle:}

Necessarily, for any persons $S 1, S 2$, and any moral proposition $p$ : If $S_{1}$ believes $p$ on the basis of intuiting $p$ and knows that $S 2$ believes some contrary of $p$ on the basis of a corresponding contrary intuition, this constitutes a defeater for $S 1$ 's continued acceptance of $p$.

Here is how we should understand this principle. The defeater mentioned in the consequent of the Concessive Principle is supposed to be a prima facie reason for $S 1$ to give up her intuitively grounded belief in $p$. This is merely a prima facie reason: $S 1$ can in principle remain justified in believing $p$ if she has available some other reason (besides her intuition) for believing $p$ or if she has some undefeated defeater-defeater that would allow her to dismiss the contrary intuiter as more likely to be mistaken. It's characteristic of brute conflicts in intuition to leave us without room for these counter-manoeuvres. Knowing that we disagree due to some brute conflict in intuition requires establishing that the other person doesn't hold the opposing view due to some epistemic fault: they just 'see' things differently. Alternative lines of justification are unavailable: the issue involves some sufficiently fundamental principle about which nothing more can be said than that it strikes us as correct. Hence, given the Concessive Principle, we ought then to suspend judgment in such cases.

Much of my argument in this paper is focused on establishing a more basic principle, from which the Concessive Principe follows. This more basic principle asks us to assign default trust to the moral intuitions of others - the very same trust that we assign to our own. More exactly: 


\section{Parity of Trust:}

Necessarily, for any persons $S 1, S 2$, and any moral proposition $p$ : If $S_{1}$ knows that $S 2$ has the intuition that $p, S 1$ has prima facie justification for believing $p$ of the same strength as $S 1$ would have if, all else being equal, $S 1$ were to have the intuition that $p$.

The Concessive Principle follows from Parity of Trust quite straightforwardly. More importantly, I think that assigning default trust to the moral intuitions of others is not only sufficient, but also necessary to establish the concessive view about brute conflicts of intuition that I favour: brute conflicts in intuition require suspension of judgment only if there is this kind of fundamental parity of trust. I'll support this claim in section 2. Thus, the question of whether we ought to assign default trust to the moral intuitions of others is where the action is and where I concentrate my efforts in this paper. This makes my approach distinctive. Whereas a number of philosophers have argued for positions similar to the Concessive Principle, they have failed to properly address questions about epistemic trust that are key to determining the truth or falsity of this principle. ${ }^{2}$

The argument I offer for Parity of Trust I call the A Priori Parity Argument. Here is an informal sketch. We permissibly rely on our own moral intuitions without requiring prior evidence of their reliability. A fundamental self/other asymmetry in moral epistemology is unacceptable, and so we should extend the same trust to the intuitions of others. Therefore, the moral intuitions of others provide equally good prima facie reasons for us to believe the propositions they intuit.

This represents a revision - a radicalization, if you will - of a line of argument previously developed by Alan Gibbard (1990) and Richard Foley (2001), dubbed the Parity Argument by Frederick Schmitt (2002). My argument uses a priori considerations to ground

\footnotetext{
${ }^{2}$ See, e.g., Besong (2014), McGrath (2008), Setiya (2012: 23-30), Sinnott-Armstrong (2002). Others have been more sensitive to these issues: see Hills (2010), Pasnau (2015), Wedgwood (2010).
} 
a form of self-other parity that is grounded a posteriori under the Parity Argument. This makes my argument more radical in its implications regarding disagreement. My revised argument is also narrowly focused on the kind of trust we assign to our moral intuitions, for reasons I'll explain.

Throughout this paper, I remain relatively non-committal as to the exact nature of moral intuitions, avoiding well-known controversies in contemporary epistemology and the philosophy of mind, such as the extent to which intuitions have a phenomenal character like that of perceptual states. ${ }^{3}$ I assume that intuitions are non-doxastic mental states of the kind elicited when a moral verdict 'strikes us' as true without being the conclusion of any chain of explicit reasoning, as when we consider particular scenarios, such as trolley cases, or general principles, such as Pareto improvements are pro tanto good. I take it we are each familiar with this kind of experience and I'll assume this provides a sufficient grip on the relevant phenomenon for the argument to proceed. So far as I'm aware, philosophically controversial questions about the nature of intuitions as mental states do not impact on the normative conclusions I mean to draw in this paper.

I should also offer a quick terminological note about how I'm going to be using the word 'trust'. When I speak of people trusting their own moral intuitions, I'm relying on a thin notion of intellectual self-trust, according to which trust in a cognitive faculty means simply relying on its outputs. There are other cognitive phenomena that have at least as good a claim to being called 'intellectual self-trust', including Karen Jones's (2012) conception of a reflexive affective attitude involving optimism regarding one's cognitive competence in a given domain. The thin notion of epistemic trust on which I'm relying isn't supposed to be a rival to this thicker notion, but simply an attempt to zero in on a different epistemic phenomenon.

\footnotetext{
${ }^{3}$ On which, see Bealer (1998), Chudnoff (2013), Huemer (2005).
} 
Here is the plan for the paper. In section 2, I provide a bit of dialectical context for my argument. I say something about the epistemological distinctiveness of the kind of disagreement that interests me, and I explain the relationship between my argument and that advanced by Gibbard and Foley. Finally, I lay out the reasons why I think that brute conflicts in moral intuition require concession only if something like Parity of Trust is true.

In section 3, I argue for a particular interpretation of the suggestion that we are justified in relying on our own moral intuitions without first having gained evidence of their reliability. As we'll see, there are some prima facie plausible interpretations of this informal notion of default self-trust that cannot be combined with the denial of a fundamental self/other asymmetry to entail Parity of Trust.

In section 4, I then argue against the posit of a fundamental self-other asymmetry. Here, I'm going to transpose Parfit's (1984) argument that identity doesn't matter for survival to show that identity is irrelevant for moral epistemology in just the way I says it is. I also consider and reject the possibility of attaching epistemic significance to Parfit's Relation R.

\section{Context}

The key aim of this section is to situate my argument within the broader context of the contemporary epistemology of disagreement, making clear why I approach the issue of brute conflicts in intuition in the way I do. I'll explain why disagreements of this kind raise unique epistemological questions and how my approach to these questions differs from that of the philosophers from which I've otherwise drawn inspiration. Lastly, I explain why I've found it necessary to address these questions by drawing our attention to fundamental issues concerning our trust in others and the relevance of identity to epistemic normativity.

As advertised, the first thing I want to do in this section is address the distinctiveness of our subject matter. Many philosophers defend concessive views about 
disagreement. The kind of disagreement in which I'm interested is of a special kind, and I don't necessarily recommend a concessive approach for other kinds of disagreement.

Firstly, I'm specifically interested in disagreement about moral questions. Some philosophers believe disagreements of this kind are governed by special epistemic norms. Alison Hills (2010) argues that disagreements that would otherwise require suspension of judgment needn't do so if the matter in dispute is moral; the word of others generally counts for less on moral questions. ${ }^{4}$ It's for this reason that I tailor my A Priori Parity argument as I do. A more general argument that didn't look specifically to the moral case could be dismissed by Hills as carrying no clear implications for moral disagreement.

In addition, it's quite possible that other kinds of disagreements come with their own epistemic norms. I am much less inclined, for example, to defend a concessive approach for disagreements about what's funny or disgusting. ${ }^{5}$ Adam Elga (2010) thinks that disagreement about disagreement is governed by sui generis norms. In general, I make no assumption about how my conclusions about moral disagreement generalize to similar nonmoral disagreements. (Nor do I assume they will not generalize.)

Even if we reject the view that the epistemology of moral disagreement is in any respect sui generis, we might still think that disagreements involving brute conflicts of intuition have unique properties. In particular, disagreements that boil down to brute conflicts in intuition don't seem to fit the model of peer disagreement.

Peer disagreement occurs when (i) $S 1$ and $S 2$ adopt incompatible epistemic attitudes with respect to some proposition, $p$ (ii) $S_{1}$ and $S_{2}$ share any evidence relevant to the question of whether or not $p$, (iii) $S_{1}$ and $S_{2}$ are on average equally reliable in assessing $p$ type issues, and (iv) (i)-(iii) are common knowledge for $S_{1}$ and $S 2$. Supposing that intuitions provide evidence for the propositions that figure as their contents, disagreements deriving

\footnotetext{
${ }^{4}$ For similar views, see Crisp (2014), Howell (2012), McGrath (2011), Nickel (2001), Wolff (1970).

${ }^{5}$ On disagreements about taste, see Egan (2010).
} 
from different underlying intuitions fail the condition of shared evidence: these disagreements arise precisely because people initially confront different considerations pointing toward incompatible conclusions. In addition, the kind of disagreements that concern me need not involve individuals who are and/or ought to recognize one another as equally reliable in assessing moral questions, precisely because we are interested in cases where people disagree fundamentally about morality. ${ }^{6}$

I'm solely interested in moral disagreements that reflect brute differences in intuition. I make no argument as to whether we should be concessive or steadfast in the face of peer disagreement. If you hold a steadfast view about peer disagreement like Thomas Kelly (2005, 2010), you are not thereby ruled out from accepting my conclusion (and vice versa). Similarly, if you defend a concessive view about peer disagreement like Adam Elga (2007) or David Christensen (2007), this doesn't commit you to endorsing the Concessive Principle (and vice versa).

As noted, in thinking about brute moral disagreements, I take as my starting point the Parity Argument due to Gibbard (1990) and Foley (2001). I'll now explain how the original Parity Argument works and why I mean to revise it so as to derive the kind of concessive view about moral disagreement that I favour.

I'll focus on Foley's presentation of the argument, which is the most fully developed. The underlying logic of the argument is encapsulated in Foley's image of self-trust radiating outward. Gibbard and Foley assume that unless we concede defeat to the skeptic, we have to accept that we are justified in relying on our own cognitive faculties without prior evidence of their reliability: we are permitted default self-trust. This raises the question of why we shouldn't extend similar trust to others. Gibbard and Foley believe that we should. The basis of this obligation is not any a priori arbitrariness attaching to a fundamental self-other

\footnotetext{
${ }^{6}$ Cf. Elga (2007: 492-497).
} 
asymmetry. (More on that later.) Rather, Gibbard and Foley rely on a host of empirical considerations concerning the relationship between our own cognitive faculties and those of the people around us. For example, due to our extensive reliance on testimony from early infancy, our most fundamental concepts and assumptions are said to derive from others. Our awareness of this fact pressures us to extend default trust outward. Trust should also be extended when we know that our cognitive faculties have been shaped by similar developmental environments or embody broad commonalities of function.

Though the Parity Argument is used by Gibbard and Foley to argue that we can be permitted to rely on the word of others without positive evidence of their reliability, the argument does not establish a universal carte blanche on this front. Hence, the Parity Argument is not an argument for Testimonial Non-Reductionism, understood as the view according to which, necessarily, for any $S_{1}, S_{2}, p$, if $S_{1}$ knows that $S_{2}$ testified that $p, S_{1}$ has prima facie justification for believing $p$ - even if $S 1$ has no evidence that $S 2$ 's testimony with respect to $p$-type issues is reliable. ${ }^{7}$ Ultimately, the Parity Argument is quite limited in the extent to which it requires us to trust: the argument implies that default trust should be extended outward only in those cases where we have empirical reason to believe that others' cognitive faculties are related to ours in the ways described above. By grounding our trust in others in empirical evidence of their similarity to us, the argument ends up supporting a broadly steadfast approach to disagreement. As Foley (2001: 108-117) notes, evidence of disagreement should be thought to impede the outward radiation of trust by providing evidence that others' cognitive faculties are not relevantly similar to ours, thus undermining the consistency requirement that grounds the outward extension of trust.

I think the Parity Argument undersells the degree to which we are required to treat others as epistemic equals. In my $A$ Priori Parity Argument, I replace the empirical considerations discussed by Gibbard and Foley with an appeal to the a priori unacceptability

\footnotetext{
${ }^{7}$ For this view, see Burge (1993), Coady (1992), McDowell (1994), Reid (1764/1997), Schmitt (1999).
} 
of a self-other asymmetry regarding default trust in moral epistemology. Given the permission for default self-trust, this entails trusting the moral intuitions of others just as we trust our own, regardless of any empirical evidence of shared influence or constitution. The default response to disagreement in intuition, then, is suspension of judgment.

Before I proceed to the argument itself, there is one remaining issue that deserves to be cleared up. I'm tying my discussion of the epistemic significance of brute conflicts in intuition to some pretty fundamental questions in moral epistemology. We're going to be looking at deep questions about our trust in others and the relevance of identity to epistemic normativity. This might seem like overkill. Granted, if we want to say that contrary intuitions always provide prima facie reasons for belief-revision, then perhaps these are the sort of questions we have to take up. But if we want to know whether the sorts of brute disagreements that we find in ordinary life provide defeaters, do we really need to go so far as to debate the merits of the Concessive Principle and Parity of Trust? Consider a weaker principle of defeat, with significantly greater prima facie plausibility:

\section{The Less Concessive Principle:}

Necessarily, for any $S 1, S 2$, and any moral proposition $p$ : If $S 1$ believes $p$ on the basis of intuiting $p$, knows that $S 2$ 's intuitions are reliable with respect to $p$-type issues, and knows that $S 2$ believes some contrary of $p$ on the basis of a corresponding contrary intuition, this constitutes a defeater for $S 1$.

The brute conflicts in intuition that we seem to encounter in everyday life might be thought to involve people whose moral beliefs agree with our own to such an extent that we should think them broadly reliable on moral issues, and perhaps even as reliable as ourselves when we set aside the mater in dispute. Can't we then simply appeal to the Less Concessive Principle in arguing that such disagreements require us to suspend judgment? 
I think this line of reasoning is unpromising for two reasons. Firstly, the reasoning set out in the previous paragraph relies on the idea that we count others' moral beliefs and/or intuitions as broadly reliable because they tend to agree with the moral facts as we see them. This gives our own moral outlook authority when it comes to the reliability of others. Hence, when others' moral beliefs and/or intuitions disagree with our own, this would seem to provide reason for us to dismiss their view as mistaken and lower our estimate of their reliability accordingly. ${ }^{8}$ My view here parallels Foley's approach to disagreement: if others get counted as trustworthy on the basis of their similarity to us, points of disagreement counteract the outward extension of trust and allow us to disregard the opinions of others.

Here is a second problem. You could accept the Less Concessive Principle but deny that brute conflicts of intuition provide defeaters, even in cases where you know that the person with whom you disagree has moral intuitions or beliefs that are reliable in general. The principle comes into play only when $S 1$ has evidence that $S 2$ 's intuitions on $p$-type issues are reliable. It is not obvious how to type issues. You might think that when $p$ is a moral proposition, the relevant type is moral propositions in general. It could be said, however, that the force of discovering brute disagreements in intuition is to place the matter in dispute in a category of its own. In that case, the $p$ about which we disagree would not belong to a type for which I have prior evidence of your reliability and the Less Concessive Principle wouldn't apply. Imagine that our moral intuitions and beliefs are exactly identical, so far as is possible, but for the fact that, when it comes to the morality of consensual incest, you think it's wrong, I think it's surely permissible, and we have a brute clash of intuitions. Knowing that two individuals who agree on other issues in ethics nonetheless get locked into intractable disagreement when it comes to the morality of consensual incest, I receive evidence that people's track record on those other issues doesn't allow one to predict

${ }^{8}$ Cf. Enoch (2010). 
judging the morality of consensual incest correctly any better than would flipping a coin. I would therefore seem justified in treating the morality of incest as an issue of a kind on which I have poor evidence from which to predict that you'll judge the matter correctly. In that case, the Less Concessive Principle would be inapplicable.

In light of these considerations, I think it most promising to address the significance of brute conflicts in intuition by thinking in terms of the more fundamental epistemological issues on which I concentrate. If we are to view others' foundational moral intuitions as capable of defeating our own, we need a picture on which there is some kind of fundamental parity between us. That's what I intend to supply.

\section{Default Self-Trust}

This section is intended to argue for a particular interpretation of the claim that we enjoy default self-trust with respect to our own moral intuitions. There are a variety of ways in which to interpret this proposal, some of which won't support the overarching argument of this paper. I'm going to consider some of the key interpretative possibilities and argue for the superiority of the one that allows me to run the A Priori Parity Argument. A key part of my argument in this section will involve reflecting on the epistemic significance of intrapersonal intuitive disagreement.

As a first approximation, we might adopt the following interpretation of what it means to enjoy default self-trust with respect to our moral intuitions:

\section{Default Self-Trust:}

Necessarily, for any $S, p$ : If $S$ has the intuition that $p, S$ has prima facie justification for believing $p$.

Since it grants a uniform epistemic significance to our moral intuitions and takes no account of characteristically externalist conditions such as reliability, Default Self-Trust might be 
thought to commit us to some form of epistemic internalism. Now, in one respect, I would be fine with that: I think internalism is more plausible than externalism. In general, epistemologists are slightly more likely to accept or lean towards internalism. ${ }^{9}$ It would be a mistake, however, to suppose that Default Self-Trust automatically commits us to internalism.

A well-known objection to any bald reliabilist theory which counts a belief as prima facie justified just in case it's the product of a reliable belief-forming process is that it gets the wrong results in a number of non-standard cases, such as those involving clairvoyance (BonJour 1980) or evil demons (Cohen 1984). To avoid these problems, modifications to the theory have been suggested which have reliabilism implying that attributions of justification in nonstandard cases should reflect the facts of reliability in standard cases. For example, Juan Comesaña (2002) suggests we should adopt Indexical Reliabilism, according to which a belief is justified even if formed via an unreliable process, so long as it is formed via a process that is reliable in the actual world. Alvin Goldman (1986) suggests that attributions of justification are to follow the facts of reliability in what he calls 'normal worlds': "beliefs are deemed justified when (roughly) they are caused by processes that are reliable in the world as it is presumed to be." (108) Supposing that we adopt one of these revised reliabilist theories, then if moral intuitions provide prima facie justification in the actual world or in the world as it is presumed to be, Default Self-Trust follows.

Even if we assume internalism, Default Self-Trust doesn't give us what we need for the A Priori Parity Argument to work. You could in principle accept Default Self-Trust, deny the existence of any self-other asymmetry, but still reject Parity of Trust and the Concessive Principle. I'll now explain why.

\footnotetext{
${ }_{9}^{9}$ Bourget \& Chalmers (2010). On the other hand, it should be noted that the data compiled by Bourget \& Chalmers indicates that philosophers as a whole are more likely to lean toward externalism.
} 
Default Self-Trust doesn't tell us why people always have prima facie justification to believe the propositions they intuit. One means of filling this explanatory gap is to suppose that intuitions provide basic justification. ${ }^{10}$ On this view, we gain justification for believing $p$ purely by virtue of having the intuition that $p$. The capacity of our intuitions to confer justification on beliefs with corresponding contents doesn't depend on our having justification for believing any more fundamental proposition: in particular, it is independent of our having any prior entitlement to believe that our intuitions are reliable. I'll call this view Intuitive Dogmatism, owing to its similarity to Jim Pryor's (2001) Perceptual Dogmatism.

Here is an alternative view. Some philosophers reject Perceptual Dogmatism in favour of the rationalist view that each of us is entitled a priori to believe that our perceptual faculties are reliable, absent evidence to the contrary. ${ }^{11}$ This entitlement explains why we have justification for believing $p$ whenever it perceptually appears that $p$ : perceptual states do not carry basic justification; they provide justification only because we enjoy a more fundamental entitlement to believe in the reliability of perception. Similarly, someone might suppose that moral intuitions confer justification in the manner described by Default SelfTrust only because we are entitled a priori to believe that our own moral intuitions are reliable, absent evidence to the contrary. Let's call this view Intuitive Apriorism.

The choice between Intuitive Apriorism and Intuitive Dogmatism is potentially important in assessing my argument. The A Priori Parity Argument says that we are permitted default self-trust and must extend this trust to others, because a fundamental selfother asymmetry in moral epistemology is untenable. Suppose we accept Intuitive Apriorism. Then, we accept Default Self-Trust and posit as its basis each person's having a priori prima facie justification for supposing that her intuitions are reliable. In that case, the reasoning set out in the informal statement of the A Priori Parity Argument seems cogent: I have an $a$

\footnotetext{
${ }^{10}$ See Chudnoff (2013), Huemer (2005), Wedgwood (2010).

${ }^{11}$ See Cohen (2010), Reid (1764/1997), White (2006), Wright (2004).
} 
priori entitlement to believe that my moral intuitions are reliable; disallowing any fundamental self-other asymmetry, I should accept a similar principle applying to the intuitions of others. Thus, if we accept Intuitive Apriorism, we can resist the argument only by insisting that my intuitions have special epistemic significance for me.

Assuming Intuitive Dogmatism, things aren't quite so clear. On this view it's simply my having an intuition that $p$ which provides justification for me to believe $p$. The requirement to trust others expressed by Parity of Trust concerns the epistemic significance of my having evidence that others have certain intuitions. Absent certain science fiction scenarios, I can never literally have another person's intuition. At best, I can know - from the outside - that they have a certain kind of intuition. We do not have to affirm the existence of any fundamental self-other asymmetry in epistemology to rule out Parity of Trust, in that case. We need only assert a difference between having an intuition and having evidence of an intuition. It is the whole point of Intuitive Dogmatism that intuitions are mental states with a very special epistemic significance, giving rise to basic justification. Thus, it should not be too surprising if there exists this kind of asymmetry. Arguably, Intuitive Dogmatism doesn't commit us to endorsing this asymmetry. Nonetheless, it leaves room for a view that asserts the existence of an important epistemic difference between having an intuition and having evidence of one. I'll call this view Dogmatist Anti-Parity.

Dogmatist Anti-Parity is defended by Ralph Wedgwood (2010). Wedgwood understands the license for default self-trust as a permission "to form moral beliefs directly on the basis of one's current intuitions - even without any additional independent reason for regarding those intuitions as reliable" (240). He denies that there could be any requirement to extend this trust to others. There can be no such requirement because there is no way that I can exhibit the same kind of attitude of trust with respect to your intuitions that I 
exhibit with respect to my own: "It does not seem possible for me currently to form a moral belief directly on the basis of your moral intuition." (239) ${ }^{12}$

As noted, Dogmatist Anti-Parity doesn't attach any real epistemic significance to differences of identity: it's the difference between having an intuition and having evidence of an intuition that counts. Two implications make this clear. Firstly, if I could base my beliefs directly on your intuitions, I would be justified in doing so. Secondly, although my having an intuition that $p$ provides me with prima facie reason to believe $p$, my knowing that I have had or will have an intuition that $p$ should provide no such reason, of itself, to believe $p$.

This latter implication proves problematic. If my present intuitions have a special epistemic significance for me that isn't shared by my knowing that I have had or will have a similar intuition, we can draw the following implication. Unless I have independent evidence for the reliability of my past or future intuitions, I am always permitted to stick with my present intuition in cases where I know that my intuitions conflict across time. This seems to me to be the wrong view to take about intrapersonal disagreements of this kind. Consider the following case.

\section{Dancing Intuitions:}

I'm doing a bit of Trolleyology, when I read the description of Thomson's Loop Case for the first time. Having carefully considered the case, it strikes me that you are permitted to turn the trolley in the Loop Case: that's my intuition. I go to have a cigarette, forgetting all about trolleys and tracks for the time being. I then get back to work. Re-reading the description of the Loop Case with equal care, I find I now have the intuition that the agent may not turn the trolley: intuitively, that would be

\footnotetext{
${ }^{12}$ Cf. Bergmann (2010): “even after full disclosure, S1 and S2 don't have the same evidence. Reporting their apparent insights to each other is not the same as giving those apparent insights to each other. Whereas $\mathrm{S} 2$ has the apparent insight that $\sim$ p, S1 merely has the belief that S2 has the apparent insight that p." (339)
} 
wrong..$^{13}$ I remember that, minutes ago, I had the opposite intuition. Now I don't know what to think.

In this case, siding with my present intuition seems unjustified: suspending judgment seems the correct response, given that I know my intuitions dance and I have no independent reason to suppose that one or the other is more likely to be correct. ${ }^{14}$

Of itself, this needn't rule out Dogmatist Anti-Parity. After all, the view doesn't say that you should never suspend judgment in cases of intuitive disagreement. It could be said that in Dancing Intuitions, my memory of a past intuition has epistemic significance for me because I have some independent justification for supposing that my own past intuitions are reliable. However, while we can imagine certain ways in which I might have gained this kind of justification, there's no reason to think our view about Dancing Intuitions depends on interpolating this kind of detail into the example.

Here is another line of argument by which one might attempt to accommodate Dancing Intuitions without attaching any default credibility to our own past intuitions. When I discover that my intuitions on the Loop Case dance, it might be thought that this straightforwardly casts doubt on their reliability: just by noting that they disagree, I know that no more than $50 \%$ are accurate. Evidence of unreliability might then be taken to undercut my present intuition, which explains why I should suspend judgment in Dancing Intuitions.

\footnotetext{
${ }^{13}$ For empirical evidence of the instability of Loop Case intuitions, see Liao et al. (2012).

${ }^{14}$ An anonymous referee suggests that in Dancing Intuitions I might have independent reason to trust my current intuition on the assumption that it may well be the result of an incubation effect involving additional, subconscious processing of the Loop Case that confers greater reliability. But we can stipulate that I know that this is not the explanation for my change in intuition: for example, if we assume (counterfactually) that my knowledge of human moral psychology rules out effects of this kind happening over such short stretches of time. With this further stipulation, it seems clear to me that I ought to suspend judgment.
} 
While prima facie plausible, this line of reasoning ultimately falters. Here's the problem. If I were to intuit that turning the trolley in the Loop Case is permissible whilst knowing that someone else had the contrary intuition, then I would also have evidence that my intuition belongs to a reference class whose members are not generally reliable: the reference class comprising mine and my interlocutor's intuitions about the Loop Case. The defender of Dogmatist Anti-Parity doesn't want to say that there is a defeater whenever there are clashes of intuitions like this: that would be to walk right into the Concessive Principle.

How might the interpersonal case just described differ from the intrapersonal case described in Dancing Intuitions? It might be suggested that my own intuitions comprise an appropriate reference class because they arise from a common method or procedure, or because I have (more) reason to believe that they do. However, in Dancing Intuitions, the defeater that I receive seems very much localized to the one particular case on which my intuitions dance: while I should suspend judgment about the Loop Case, it doesn't seem that I am required to do the same with respect to the Trolley Case or the Footbridge Case. It is not at all plausible, however, that I am in possession of a method or belief-forming process whose proprietary domain is the Loop Case. If the defeater is due to evidence for the unreliability of the method that I use to decide the Trolley Case, this should then apply to my Trolleyology intuitions across the board. That seems mistaken. I should suspend judgment only about the Loop Case.

To accommodate Dancing Intuitions, I think we should adopt a revised interpretation of the notion of default self-trust that is intrapersonal and transtemporal, attributing equal epistemic significance to a person's own intuitions no matter where they fall in time (all else being equal). We may express this as follows: 


\section{Default Self-Trust*}

For any person $S$, and any moral proposition $p$ : If $S$ knows that $S$ has, had, or will have the intuition that $p, S$ has equally strong prima facie justification for believing $p$, all else being equal.

Default Self-Trust* straightforwardly explains why I should suspend judgment in Dancing Intuitions. It also explains why the problem is localized to my intuition about the Loop Case: I'm only aware of a dissenting verdict with respect to that case in particular.

Whereas I have been arguing that its implications for intrapersonal disagreement are the Achilles' heel of Dogmatist Anti-Parity, Wedgwood regards this aspect of his view as a strength, claiming that it gets the cases right. Speaking of future intuitions, he writes:

it does not seem so strange to me that, even if one receives the information that one will have a certain intuition in the future, one's response to this information should be guided by one's rational assessment of whether one's intuitions can be expected to become more or less reliable in future. There is also no need for this assessment to be independent of one's current intuitions. Indeed, in some cases, the very information that I will come to have a certain intuition in future gives me reason to think that my moral sensibilities will deteriorate. For example, suppose I receive the information that, in the future, I will have the intuition that it is an admirable form of toughmindedness for the police to have a policy of torturing those whom they suspect of serious crimes. This information would seem to me all by itself to make it rational for me to think that my moral intuitions will probably be less reliable in future than they are now. (241)

In spite of everything said so far, Wedgwood's claim that he can dismiss his future torture intuition seems convincing. This appears to challenge the position on transtemporal selftrust for which I've been arguing in this section. However, I believe we should remain convinced by my argument. I can readily accommodate Wedgwood's claim that he should be confident that his future intuition will be mistaken in the case described. I can do so 
without back-tracking on anything I've said so far, since Wedgwood does have independent reason to support his confidence on that point.

My reasoning here follows an approach outlined by David Christensen (2010: 8-11) in explaining why certain cases of disagreement allow for an otherwise surprising degree steadfastness. In Wedgwood's case, I'm told that my future intuition will favour torture, and nothing more. This leaves open a host of questions about what will happen to me and how I will come to hold this view, which I now regard as repugnant. I don't have to rely on the correctness of my present view in order to remain reasonably steadfast in that case. I can rely on the knowledge that, since one of us must be badly mistaken, something must have gone wrong somewhere. I can combine this knowledge with my more detailed knowledge of my present self. This should lead me to assign significant confidence to the hypothesis that I'll be subject to some relevant epistemic fault in future: my privileged knowledge about my present self allows me to rule out obvious sources of bias and poor judgment in me as I am now. ${ }^{15}$ In Dancing Intuitions, by contrast, there are no similar considerations that could support reliance on my present intuition. I know a great deal about what happens in the intervening period between the contrary intuitions, and it seems utterly arbitrary. Here, I should suspend judgment.

\footnotetext{
${ }^{15}$ An anonymous referee raises the concern that my treatment of Wedgwood's case may seem to undercut the concessive view I'm putting forward in this paper. It's important to keep in mind that The Concessive Principle for which I'm arguing leaves open that $S_{1}$ can remain justified in believing $p$ when she knows that $S_{2}$ has a conflicting intuition if she has some undefeated defeater-defeater that would allow her to dismiss the contrary intuiter as more likely to be mistaken. I think this holds true in Wedgwood's case, for the reasons explained, whereas it is characteristic of brute conflicts in intuition to leave us without such counter-manoeuvres, for reasons outlined in section 1. Thus, my treatment of Wedgwood's case does not undercut the concessive stance I think we ought to take with respect to brute conflicts in intuition.
} 


\section{No Asymmetry}

From here on, I take myself to have offered a sufficient case for Default Self-Trust*. To complete the A Priori Parity Argument, I will now argue that identity lacks the kind of epistemic significance that it would have to have for it to be the case that Default Self-Trust* is true but Parity of Trust is false. For reasons that will become clear, I'll actually be arguing for a stronger claim that denies this kind of epistemic significance to any reflexive relation, including but not limited to identity:

No Asymmetry:

There is no reflexive relation of a kind such that Default Self-Trust* could be true although Parity of Trust is false.

Now, I don't know of anyone who explicitly endorses a fundamental self-other asymmetry of the kind that No Asymmetry denies. Robert Pasnau (2015) is perhaps the closest candidate in the recent literature on disagreement. Pasnau suggests that because self-trust has intrinsic value we can be justified in remaining steadfast in cases of disagreement even if we lack any independent reason to regard our own judgment as more likely to be true. Pasnau further suggests that self-trust has especial significance in this way when disagreement involves moral questions or other issues that are central to individual self-identity. But Pasnau doesn't say explicitly whether he understands self-trust as transtemporal in the way that's implied by Default Self-Trust* or as restricted to trust in one's current beliefs and belief-forming processes.

In any case, I can imagine that a number of people would feel be inclined to deny No Asymmetry if they thought that doing so was necessary to rule out the concessive implications of the Concessive Principle. Those implications are likely to be revisionary of the way in which we actually respond to the moral intuitions of others. As Michael Huemer 
(2011) says: "very few people place as much confidence in another person's intuitions as they would place in their own." (18) Although I expect that much of this can be defended by reference to asymmetries in self-knowledge, I doubt that this is sufficient to legitimate common practice wholesale. Those hoping to avoid the Concessive Principle may posit a transtemporal self-other asymmetry in moral epistemology rather than face the consequences. I want to argue that this would be a mistake.

In arguing for No Asymmetry, I'm going to draw on cases first used by Parfit (1984) in questioning the practical significance of the boundary between self and other, in his discussion of identity fission. In doing so, I'm going to be assuming a psychological criterion of personal identity. This assumption is designed purely to focus our discussion by fixing in mind a plausible supervenience base for identity over time. The argument can be made on any account of personal identity that allows for fission, and this includes a great many others besides the psychological account. ${ }^{16}$

Fission occurs when the relations that normally support identity over time hold between one past or present individual and two future individuals. Thus, if we suppose that identity over time is normally supported by psychological continuity, a case of fission is one in which two later individuals are psychologically continuous with one present individual. Parfit describes such a case, as follows:

My Division. My body is fatally injured, as are the brains of my two brothers. My brain is divided, and each half is successfully transplanted into the body of one of my brothers. Each of the resulting people believes that he is me, seems to remember my life, has my character, and is in every other way psychologically continuous with me. And he has a body that is very like mine. (254-255)

${ }^{16}$ See Noonan (2003: 125-127). 
Fission cases are important for our understanding of the metaphysics of identity. If we wish to maintain the psychological criterion of personal identity in some form whilst respecting the intuition that there are two distinct individuals existing at the end of My Division, we cannot say that identity over time consists in psychological continuity. Instead, we must say that identity consists in non-branching continuity.

Fission cases may also tell us something important about the ethical significance of identity. As noted, we tend to think that some degree of prudential concern is rational. Consider an adult person, Sally. Amongst all those individuals who exist in the future, we are inclined to think that Sally should be particularly concerned with the wellbeing of her future self: she has a 'stake' in that person's welfare that she doesn't have in the welfare of others. We might believe that, if this form of prudential concern is rational, it's the relation of identity that makes it so: Sally has a special 'stake' in the wellbeing of her future self because her future self is her future self. An alternative proposal, favoured by Parfit, is that it is psychological continuity and/or connectedness - Relation $R$ - that grounds prudential concern.

When we consider cases of fission, it seems plausible that Parfit is right to favour Relation $\mathrm{R}$ as the ground of prudential concern. Suppose that identity over time consists in non-branching psychological continuity. Then, were one of the transplants in My Division to fail, I would continue to exist; it is only when both transplants are successful that I cease to exist. Two successful transplants don't seem to add up to something as bad as death. This suggests that Relation $\mathrm{R}$ must be what gives us a special 'stake' in the welfare of certain people, if anything does. This has important implications, since Relation R, unlike identity, holds by degrees and may hold to some extent amongst distinct persons - even those outside science-fictional scenarios like My Division. As Parfit says: "There is still a difference between my life and the lives of other people. But the difference is less.” (280) 
We can also use fission cases to test our intuitions about the significance of identity in moral epistemology. We are supposing that Default Self-Trust* is true. Let's then consider the following case:

\section{Possible Bisection:}

I have been fatally injured. I know that at least one half of my brain will be transplanted, and there will be psychological continuity. I know that someone with this part of my brain will later have the intuition that it is permissible to turn the trolley in the Loop Case. I don't know whether there will also be a second transplantation.

Suppose we believe that identity matters in epistemology in the way that No Asymmetry is supposed to rule out. In Possible Bisection, we should then believe that I have reason to believe that turning the trolley is permissible in the Loop Case if I gain evidence that there will not be a successful second transplantation of the same kind. By contrast, evidence that a second, successful transplantation will occur would undercut my reasons for believing that turning the trolley is permissible, because then the intuition wouldn't be mine. This holds even if I should expect the person at the end of the second transplant also to have the intuition that turning the trolley is permissible. This implication is bizarre. It just does not seem that facts about an additional transplantation could undercut my reasons for believing that turning the trolley is permissible in this way.

Even if we accept this verdict, we haven't yet established No Asymmetry. No Asymmetry denies that there is any reflexive relation such that Default Self-Trust* could be true although Parity of Trust is false. If we give up on the idea that the identity relation has any deep significance, we might be inclined to attribute this kind of significance to some 
other reflexive relation. In this respect, Relation $\mathrm{R}$ might seem a natural fall-back. I'll now argue that this inclination should be resisted.

We first need to get a little clearer on how to understand Relation R. Following Parfit, we say that connectedness consists in the holding of direct psychological connections, strong connectedness involves a sufficiently large number of such connections, ${ }^{17}$ and continuity consists in overlapping chains of strong connectedness.

Parfit offers three possible interpretations of when a direct psychological connection obtains. On what he calls the widest version, we allow any causal connection amongst mental states to subserve a direct connection: thus, we say that there is a direct connection between $S_{1}$ and $S_{2}$ if, for example, $S_{2}$ has an experience $e$ at $t 1, S_{1}$ has a memory as of $e$ at $t 2$, and the former fact figures in the causal explanation of the latter. ${ }^{18}$ Alternately, we may want to set restrictions on the nature of the causal connection between $S 2$ 's experience of $e$ and $S$ 1's memory as of $e$. Following what Parfit calls the narrow version, we might say that the apparent memory must depend on the earlier experience in the normal way. A middle position between the narrow and the widest version is the wide version, which maintains that a direct connection holds whenever the causal relation between two mental states is of a kind that reliably subserves such a connection.

I think the narrow understanding of what a psychological connection consists in is least plausible. We should despair of the possibility of finding a description of the 'normal' connection between an experience and the memory of it that could encompass the full range of possible minds, biological and artificial, whilst enforcing any genuine restrictions over

\footnotetext{
${ }_{17}$ According to Parfit: "we can claim that there is enough connectedness if the number of direct connections, over any day, is at least half the number that hold, over every day, in the lives of nearly every actual person." (206)

${ }^{18}$ Memory is not the only direct psychological connection in Parfit's exposition of the psychological criterion, but it is most useful for discussing the difference between the narrow, wide, and widest versions.
} 
and above those imposed by the wide interpretation of connectedness. Human memory works in a particular way and exhibits certain characteristic properties, such as 'chunking' and the power law of learning. Other memory systems might work very differently whilst being memory systems nonetheless. ${ }^{19}$

If we assume that the wide or widest understanding of psychological connectedness is right, it can then be shown that granting epistemic significance to Relation $\mathrm{R}$ would have absurd consequences. Testimony is, I assume, a reliable means of getting a belief from one brain to another: there must therefore be a direct connection between myself and another whenever I believe a sincere assertion, and so some degree of R-Relatedness. Consider, then, the following case:

\section{Gullible bootstrapping:}

I am listening to a speaker making various assertions. I know that the assertions correspond to the contents of her intuitions. Assume that I have no reason to believe any of her assertions: accepting any of them would be unjustified. ${ }^{20}$ Nonetheless, I believe what she says, accepting an increasing number of her assertions as true.

\footnotetext{
${ }^{19}$ See Clark (2005) and Sprevak (2009).

${ }^{20}$ Can we assume that I am not justified in believing what the speaker asserts just because I have no positive reason to believe her? As noted by an anonymous referee, this begs the question against Testimonial NonReductionism. But I'm inclined to think that no questions are begged against the view at issue here, as it would be puzzling to endorse Testimonial Non-Reductionism alongside the view under consideration. The latter is supposed to restrict default trust in the intuitions of others to conditions of R-relatedness whereas the latter allows us to exhibit default trust with respect to any and all testimony, absent defeaters. Someone combining these views would have to believe that when $S_{1}$ knows that $S_{2}$ has the intuition that $p$ and there is no Rrelatedness between them, $S 1$ thereby gains no prima facie justification for believing $p$ - unless $S_{1}$ hears $S_{2}$ assert $p$, in which case she does gain justification to believe $p$, even if she knows that $S_{2}$ asserts $p$ merely because $p$ seems intuitive to her. This view strikes me as deeply implausible.
} 
Suppose I must extend default trust to the intuitions of others to the extent that I have reason to believe that I am R-Related to them. This implies that as I unjustifiably begin to accept the speaker's assertions, I gain increasing justification for accepting further assertions; I pull myself towards justified trust by the bootstraps of my own gullibility. This seems unacceptable: if I am not justified in accepting her assertions at the outset in the case above, I surely don't end up any better off on this front by violating my epistemic obligations.

Of course, the degree of R-relatedness that we could expect to obtain in any realistic analogue of Gullible Bootstrapping is very slight, and so any reasons for trust that I acquire would be equally slight. We may not be very confident that our intuitions are reliable in discriminating between cases where I gain no reason to $\phi$ and those in which I gain only very slight reason to $\phi .{ }^{21}$ But what seems problematic in Gullible Bootstrapping is not merely our intuitive sense there is no difference in terms of my reasons for believing the speaker's assertion when we compare the beginning and the end of the vignette, but in addition that any view which says otherwise involves a bizarre picture of epistemic normativity on which a method of belief-formation that is initially irrational can in principle be made rational by sufficient repetition.

In light of this, I think we should reject the idea that Relation $\mathrm{R}$ has the kind of epistemic significance we've been considering. Relation $\mathrm{R}$ was the natural fallback once we decided that identity couldn't have any fundamental epistemic significance. Now Relation R is out of the picture too. There is, it seems to me, no natural fallback waiting to take over once Relation $\mathrm{R}$ is dismissed. It seems most plausible that there is no reflexive relation with the kind of epistemic significance that could make it the case that Default Self-Trust* is true but Parity of Trust is false. That, of course, is just what No Asymmetry says. So No Asymmetry is true.

\footnotetext{
${ }^{21}$ Cf. Schroeder (2007: 92-97). I am grateful to an anonymous referee for raising this objection.
} 


\section{Conclusion}

I have now argued for both Default Self-Trust* and No Asymmetry. Together, these imply Parity of Trust, which entails the Concessive Principle. Thus, we should accept that conflicts in intuition provide defeaters. As I explained in the introduction, it is characteristic of brute conflicts in intuition to leave little room for defeater-defeaters or alternate lines of justification. Thus, if we accept the Concessive Principle, we should think that we ought typically to suspend judgment when faced with brute conflicts in intuition.

Of course, I haven't pinpointed where I think moral disagreements reduce to brute conflicts in intuition. In some cases, establishing that we disagree in this way is relatively easy, as when two long-standing colleagues consider a new thought-experiment and find that their intuitions differ. In other cases, establishing that a disagreement is traceable to brute conflicts in intuition may be more difficult and correspondingly uncertain. This applies especially if we want to make the case that a brute conflict in intuition underlies some well-known disagreement in normative or applied ethics, where each side takes their position to be supported by arguments the other should accept. Diagnosing a clash of intuitions in such cases will typically involve attempting a careful hermeneutic reconstruction of the underlying dialectic, designed to reveal that the dispute rests ultimately with certain moral premises that one side finds intuitive and the other does not. Any such reconstruction is bound to be controversial.

I suspect that whereas many philosophers agree that some questions in moral philosophy boil down to brute differences of intuition, there is considerable disagreement as to exactly which questions those are. How we should factor in this kind of higher-level disagreement in responding to moral controversies is a matter for another time. 


\section{References.}

Abarbanell, Linda \& Hauser, Marc D. 2010. Mayan morality: an exploration of permissible harms. Cognition 115, 207-224.

Bealer, George. 1998. Intuition and the autonomy of philosophy. In M.R. DePaul and W. Ramsey (Eds.), Rethinking intuition (p. 201-240). New Jersey: Rowmand \& Littefield.

Bergmann, Michael. 2010. Rational disagreement after full disclosure. Episteme 6, 336-353.

Besong, Brian. 2014. Moral intuitionism and disagreement. Synthese forthcoming.

Bourget, David \& Chalmers, David J. 2010. The PhilPapers survey: results. Last accessed 24.01.2014: <http://philpapers.org/surveys/results.pl>

BonJour, Laurence. 1980. Externalist theories of knowledge. Midwest Studies in Philosophy 5, $53-74$.

Burge, Tyler. 1993. Content preservation. Philosophical Review 102, 457-488.

Christensen, David. 2007. Epistemology of disagreement: the good news. Philosophical Review 116, 187-217.

Christensen, David. 2010. Disagreement, question-begging, and epistemic self-criticism. Philosophers' Imprint 1 1, 1-22.

Clark, Andy. 2005. Intrinsic content, active memory, and the extended mind. Analysis 65, 111.

Coady, C.A.J. 1992. Testimony: a philosophical study. Oxford: Clarendon Press.

Cohen, Stewart. 1984. Justification and truth. Philosophical Studies 46, 279-295.

Cohen, Stewart. 2010. Bootstrapping, defeasible reasoning, and a priori justification. Philosophical Perspectives 24, 141-159.

Comesaña, Juan. 2002. The diagonal and the demon. Philosophical Studies 110, 249-266.

Crisp, Roger. 2006. Reasons and the good. Oxford: Oxford University Press.

Crisp, Roger. 2014. Moral testimony pessimism: a defence. Aristotelian Society Supplementary Volume 88, 129-143. 
Doris, John M. \& Plakias, A. 2008. How to argue about disagreement: evaluative diversity and moral realism. In W. Sinnott-Armstrong (Ed.), Moral psychology, volume 2: the cognitive science of morality: intuition and diversity (p. 303-322). Cambridge, MA: MIT Press.

Driver, Julia. 2006. Autonomy and the asymmetry problem for moral expertise. Philosophical Studies 128, $619-644$.

Egan, Andy. 2010. Disputing about taste. In Richard Feldman \& Ted Warfield (Eds.), Disagreement (p. 247-284). Oxford: Oxford University Press.

Elga, Adam. 2007. Reflection and disagreement. Nô̂s 41, 479-502.

Elga, Adam. 2010. How to disagree about how to disagree. In Richard Feldman \& Ted Warfield (Eds.), Disagreement (p. 175-186). Oxford: Oxford University Press.

Enoch, David. 2010. Not just a truthometer: taking oneself seriously (but not too seriously) in cases of peer disagreement. Mind 119, 953-997.

Foley, Richard. 2001. Intellectual trust in oneself and others. Cambridge: Cambridge University Press.

Gibbard, Alan. 1990. Wise choices, apt feelings: a theory of normative judgment. Cambridge, MA: Harvard University Press.

Goldman, Alvin I. 1986. Epistemology and cognition, Cambridge, MA: Harvard University Press.

Haidt, Jonathan. 2001. The emotional dog and its rational tail: a social intuitionist approach to moral judgment. Psychological Review 108, 814-834.

Haidt, Jonathan. 2007. The new synthesis in moral psychology. Science 316, 998-1002. Hills, Alison. 2010. The beloved self: morality and the challenge from egoism. Oxford: Oxford University Press.

Howell, Robert J. 2012. Google morals, virtue, and the asymmetry of deference. Noûs 48, $389-415$.

Huemer, Michael. 2005. Ethical intuitionism. Basingstoke: Palgrave MacMillan. 
Huemer, Michael. 2011. Epistemological egoism and agent-centred norms. In Ted Dougherty (Ed.), Evidentialism and its Discontents (p. 17-32). Oxford: Oxford University Press.

Jones, Karen. 2012. The politics of intellectual self-trust. Social Epistemology 26, 237-51.

Kelly, Thomas. 2005. The epistemic significance of disagreement. In Tamar Gendler \& John Hawthorne (Eds.), Oxford studies in epistemology, Volume 1 (p. 167-196). Oxford: Oxford University Press.

Kelly, Thomas. 2010. Peer disagreement and higher-order evidence. In Richard Fumerton \& Ted Warfield (Eds.), Disagreement (p. 111-174). Oxford: Oxford University Press.

Lackey, J. (2008). Learning from words: testimony as a source of knowledge. Oxford: Oxford University Press.

Liao, S. Matthew, Alex Wiegmann, Joshua Alexander \& Gerard Vong. 2012. Putting the trolley in order: experimental philosophy and the loop case. Philosophical Psychology 25, 661671.

McDowell, John. 1994. Knowledge by hearsay. In B. K. Matilal \& A. Chakrabati (Eds.), Knowing from words: Western and Indian philosophical analysis of understanding and testimony (p.195-224). Dordrecht, The Netherlands: Kluwer.

McGrath, Sarah. 2008. Moral disagreement and moral expertise. In R. Shafer-Landau (Ed.), Oxford Studies in Metaethics, Volume 3 (p.87-108). Oxford: Oxford University Press. McGrath, Sarah. 2011. Skepticism about moral expertise as a problem for moral realism. Journal of Philosophy 108, 111-137.

Nickel, Philip. 2001. Moral testimony and its authority. Ethical Theory and Moral Practice 4, 253-266.

Noonan, Harold. 2003. Personal identity, 2nd ed. London: Routledge. Parfit, Derek. 1984. Reasons and persons. Oxford: Oxford University Press. 
Pasnau, Robert. 2015. Disagreement and the value of self-trust. Philosophical Studies 172, $2315-2339$.

Pryor, James. 2000. The skeptic and the dogmatist. Noûs 34, 517-549.

Reid, Thomas. 1764/1997. An inquiry into the human mind: on the principles of common sense. Edinburgh: Edinburgh University Press.

Schmitt, Frederick. 1999. Social epistemology. In J. Greco \& E. Sosa (Eds.), The Blackwell Guide to Epistemology (p.354-382). Oxford: Basil Blackwell.

Schmitt, Frederick. 2002. Testimonial justification: the Parity Argument. Studies in History and Philosophy of Science Part A 33, 385-406.

Schroeder, Mark. 2007. Slaves of the passions. Oxford: Oxford University Press.

Setiya, Kieran. 2012. Knowing right from wrong. Oxford: Oxford University Press.

Sidgwick, Henry. 1906/1981. The methods of ethics, 7th ed. Cambridge: Hacking.

Sinnott-Armstrong, Walter. 2002. Moral relativity and intuitionism. Philosophical Issues 12, $305-328$

Sprevak, Mark. 2009. Extended cognition and functionalism. Journal of Philosophy 106, 503527.

Wedgwood, Ralph. 2010. The moral evil demons. In R. Feldman \& T. A. Warfield (Eds.), Disagreement (p. 216-246). Oxford: Oxford University Press.

White, Roger. 2006. Problems for dogmatism. Philosophical Studies 131, 525-557.

Wolff, Robert Paul. 1970. In defense of anarichism. New York, NY: Harper \& Row. 32

Wright, Crispin. 2004. Warrant for nothing (and foundations for free)? Aristotelian Society Supplementary Volume 78, 167-212. 